\title{
Echocardiographic Evaluation of Cardiac Status in Patients with Chronic Obstructive Pulmonary Disease
}

\author{
Mohiuddin $\mathrm{M}^{1}$, Chowdhury $\mathrm{AW}^{1}$, Islam $\mathrm{KN}^{1}$, Amin $\mathrm{MG}^{1}$, Hoque $\mathrm{ATMM}^{1}$, Saha $\mathrm{C}^{1}$, \\ Kader $\mathrm{AKMF}^{1}$, Haque $\mathrm{A}^{1}$

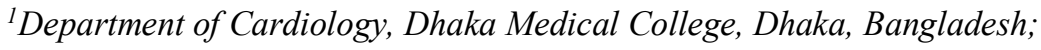

\begin{abstract}
Background: Chronic Obstructive Pulmonary Disease (COPD) is a global health burden having systemic and extrapulmonary manifestations. Among them cardiovascular changes are the major comorbidity associated with COPD, responsible for significant morbidity and mortality. Echocardiography is one of the simplest and noninvasive tools in assessing these changes.
\end{abstract}

Objective: To evaluate the echocardiographic changes in patients with chronic obstruction palmonary disease.

Methods: A cross sectional observational study was carried out in Department of Cardiology and Department of Respiratory Medicine, Dhaka Medical College Hospital from July, 2018 to June, 2019. Total 98 COPD patients were included in the study. They underwent spirometry in Department of Respiratory Medicine and echocardiography in Department of Cardiology. Data was collected from the patients and recorded in a structured report form.

Results: Significant echocardiographic abnormalities were present in $51.02 \%$ patients. Most common echocardiographic change was pulmonary hypertension (43.9\%). Other echocardiographic findings were dilated RA \& RV (36.7\%), RVH (35.7\%), LV diastolic dysfunction (30.6\%) and RV systolic dysfunction (9.2\%). Echocardiographic signs of pulmonary hypertension, dilated RA \& RV, RVH, RV systolic dysfunction and LV diastolic dysfunction were correlated with the severity of the disease. Though echocardiographic change of pulmonary hypertension was uncommon in COPD stage $1 \& 2$, but it was very common in stage $3(45.7 \%)$ \& stage $4(92.9 \%)$.

Conclusion: This study showed that echocardiographic changes were very common among the COPD GOLD stage $3 \& 4$ patients. Though these changes were infrequent among mild COPD patients but their severity increased with increasing stage of COPD.

Keywords: COPD, Echocardiography, Pulmonary hypertension, Cor pulmonale

\section{Introduction}

Chronic Obstructive Pulmonary Disease (COPD) is a disease of progressive airflow limitation that is not reversible. It causes high mortality and morbidity as well as high healthcare costs and a significant burden in the form of disability and impaired quality of life. ${ }^{1}$

COPD is a complex systemic disease that has both pulmonary and extrapulmonary manifestations. ${ }^{2,3}$ The most frequent and most important disease coexisting with COPD is cardiovascular diseases. ${ }^{4}$ Nearly half of all hospitalizations $\&$ one third deaths of COPD patients are due to cardiovascular causes specially when FEV1 $<50 \%$ predicted. ${ }^{5}$ With every $10 \%$ decrease in FEV1, all-

*Correspondence: Muhammad Mohiuddin, Department of Cardiology, Dhaka Medical College, Dhaka, Bangladesh.

e-mail:dr.mohiuddin62@gmail.com; ORCID:0000-0001-5711-4015 cause mortality increases by $14 \%$ and cardiovascular mortality increases by $28 \%{ }^{6}$ In more advanced COPD, cardiovascular diseases are responsible for $20-25 \%$ of all deaths. ${ }^{7}$

COPD impacts on pulmonary vasculature and leads to the development of pulmonary hypertension, right ventricular hypertrophy (RVH), right ventricular (RV) \& ultimately left ventricular (LV) dysfunction. Due to ventricular interdependency, raised right sided pressure shifts the interventricular septum to left and may increase LV end diastolic pressure resulting in left ventricular diastolic dysfunction (LVDD). Also LV systolic dysfunction may occur. The mechanism of abnormal LV systolic performance in COPD patients are unclear but may be due to hypoxemia and acidosis; concurrent coronary artery disease; ventricular interdependence which would in turn increase LV end diastolic pressure, decrease venous return and 
diminished LV stroke volume \& cardiac output and large swings in intrathoracic pressure. ${ }^{8}$

Echocardiography provides a rapid, noninvasive and accurate modality for the evaluation of right ventricular function, right ventricular filling pressure, tricuspid regurgitation, left ventricular function and valvular function.

There are limited studies and research into the cardiac changes secondary to COPD. Most of the studies have analyzed the relation of COPD with several isolated cardiac changes. No such study is available in our country.

The aim of this study was to evaluate the cardiac changes in patients of COPD by echocardiography. Early detection of cardiac dysfunction in COPD patients can help us to take necessary steps and interventions to halt the progression of the disease and to mitigate its array of complications, thus also contributing to improve the quality of life in such patients.

\section{Materials and Methods}

This cross-sectional observational study was conducted in Dhaka Medical College Hospital (DMCH), Dhaka from July 2018 to June 2019. All subjects were selected by purposive sampling method. COPD patients diagnosed as per GOLD 2018 criteria were included in the study. Exclusion criteria included patients with age $<40$ years, with an established diagnosis of bronchial asthma or asthma- COPD overlap syndrome, pulmonary malignancies (primary \& secondary), tuberculosis, pneumonia, known case of coronary artery disease or past history of myocardial infarction, congenital heart disease, valvular heart disease or cardiomyopathy of any type.

Patients with COPD who attended indoor and outdoor of the Department of Respiratory Medicine, Dhaka Medical College Hospital (DMCH), were assessed first by attending doctor and then evaluated by the principal investigator. Detailed history and thorough physical examination were done in all patients. Those who fulfilled the inclusion \& exclusion criteria and gave informed written consent were included in the study.

History of smoking was taken and patients were categorized as current smoker (Smoking cigarettes within 1 month), recent smoker (Stopped smoking cigarettes between 1 month and 1 year back), ex-smoker (Stopped smoking cigarettes greater than 1 year back) and nonsmoker (Never smoked cigarettes). ${ }^{9}$

The diagnosis of COPD was confirmed by spirometry done in the Department of Respiratory Medicine, DMCH. Post bronchodilator FEV1/FVC $<0.7$ was considered diagnostic of COPD. In GOLD severity classification, FEV1 was used to categorize COPD in four stages (1-4). FEV1/FVC $<0.7$ was the mandatory requirement in all four stages whereas post bronchodilator FEV $1 \geq 80 \%$ predicted was stage $1, \geq 50 \%$ but $<$ $80 \%$ predicted was stage $2, \geq 30 \%$ but $<50 \%$ predicted was stage 3 and $<30 \%$ predicted FEV1 was stage $4 .{ }^{10}$

A total of 98 COPD patients who fulfilled the inclusion and exclusion criteria were included in the study. The staging of COPD was done in Department of Respiratory Medicine, DMCH by spirometry. These COPD patients then underwent echocardiography in Department of Cardiology, $\mathrm{DMCH}$. The echocardiography was done by using Philips EPIQ 7c with multi frequency probe of 2$4.3 \mathrm{MHz}$.

The following echocardiographic parameters were studied in detail- right atrial (RA) \& right ventricular (RV) size, right ventricular hypertrophy (RVH), RV systolic function, pulmonary hypertension and LV systolic \& diastolic function. The parameters were described according to the guidelines given by American Society of Echocardiography. Pulmonary hypertension was defined as pulmonary artery systolic pressure (PASP) $\geq 35 \mathrm{mmHg}$ or mean pulmonary artery pressure (MPAP) $\geq 25 \mathrm{mmHg}$ at rest. ${ }^{11}$ According to PASP, pulmonary hypertension was divided into mild $(35-49 \mathrm{mmHg})$, moderate $(50-69 \mathrm{mmHg}) \&$ severe $(\geq 70 \mathrm{mmHg}$ ) category.

RV systolic function was detected by TAPSE $(<16 \mathrm{~mm}$ abnormal) \& FAC ( $<35 \%$ abnormal). LV systolic function was assessed by LVEF. It was detected by eyeball estimation and modified Simpson's method. LV systolic function was normal if LVEF was $>52 \% .{ }^{12} \mathrm{LV}$ diastolic function was determined by trans mitral inflow velocity $\mathrm{E}$, tissue Doppler mitral inflow velocity e', TR velocity and left atrial volume index (LAVI).Left ventricular diastolic dysfunction (LVDD) was said to be present if $\geq 2$ of the following features were present: average $\mathrm{E} / \mathrm{e}^{\prime}>14$, septal $\mathrm{e}^{\prime}$ velocity $<7 \mathrm{~cm} / \mathrm{s}$ or lateral $\mathrm{e}^{\prime}$ velocity $<10 \mathrm{~cm} / \mathrm{s}$, TR velocity $>2.8 \mathrm{~m} / \mathrm{s}$ \& LA volume index $>34 \mathrm{ml} / \mathrm{m}^{2}{ }^{13}$ 
Statistical analysis of the study was done by computer software Statistical Package for Social Science (SPSS)version 22. Confidence interval was considered at $95 \%$ level. In all case, $p$ value $<0.05$ was considered statistically significant.

\section{Results}

The characteristics of the study population are described in table I. The mean age was $56.5 \pm 10.45$ year. Maximum 33(33.7\%) patients were in 50-59 years age group which was followed by 30 (30.6\%) patients in 40-49 years age group. Among the 98 patients, $70(71.43 \%)$ were male and 28 (28.57\%) were female with a male female ratio of 2.5: 1 . Highest 29 (29.59\%) patients were unemployed. 26 $(26.53 \%)$ patients were housewives which was the second commonest occupational status. It was observed that $70(71.43 \%)$ patients were smokers. Among them 12(12.24\%) were current smokers, $14(14.29 \%)$ were recent smokers and 44(44.90\%) were ex-smokers. Among the 98 study patients 29 (29.59\%) were hypertensive, 18 (18.36\%) were diabetic and $12(12.24 \%)$ had dyslipidemia. Maximum 35 (35.7\%) study patients had GOLD stage 3 COPD. 33(33.7\%) study patients had stage $2,28(28.6 \%)$ patients had stage 4 and only $2(2 \%)$ patients had stage 1 COPD.

Table I: Characteristics of study population $(n=98)$

\begin{tabular}{|c|c|}
\hline Mean age (years) & $56.5 \pm 10.45$ \\
\hline \multicolumn{2}{|l|}{ Sex } \\
\hline Male & $70(71.43 \%)$ \\
\hline Female & $28(28.57 \%)$ \\
\hline Male: Female & $2.5: 1$ \\
\hline \multicolumn{2}{|l|}{ Occupation } \\
\hline Businessman & $11(11.22 \%)$ \\
\hline Service holder & $10(10.20 \%)$ \\
\hline Retired & $7(7.14 \%)$ \\
\hline Housewife & $26(26.53 \%)$ \\
\hline Physical labor & $9(9.18 \%)$ \\
\hline Unemployed & $29(29.59 \%)$ \\
\hline Others & $6(6.12 \%)$ \\
\hline \multicolumn{2}{|l|}{ Smoking status: } \\
\hline Current smoker & $12(12.24 \%)$ \\
\hline Recent smoker & $14(14.29 \%)$ \\
\hline Ex-smoker & $44(44.90 \%)$ \\
\hline Non smoker & $28(28.57 \%)$ \\
\hline Systemic hypertension & $29(29.59 \%)$ \\
\hline Diabetes Mellitus & $18(18.36 \%)$ \\
\hline Dyslipidemia & $12(12.24 \%)$ \\
\hline \multicolumn{2}{|c|}{ COPD severity (GOLD stage) } \\
\hline Stage 1 & $2(2.0 \%)$ \\
\hline Stage 2 & $33(33.7 \%)$ \\
\hline Stage 3 & $35(35.7 \%)$ \\
\hline Stage 4 & $28(28.6 \%)$ \\
\hline
\end{tabular}




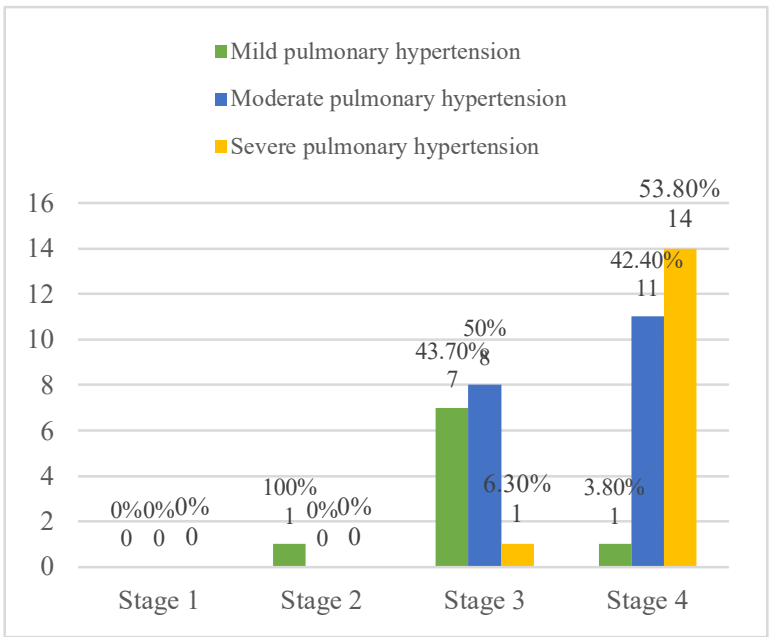

Figure 2: Distribution of severity of pulmonary hypertension among different stages of COPD patients $(n=43)$.

The table III shows the echocardiographic changes in different stages of COPD. We found that dilated RA \& RV, RVH, pulmonary hypertension, RV systolic dysfunction and LV diastolic dysfunction correlated significantly with severity of disease $(p<0.001)$.

Table III: Association of echocardiographic changes with different stages of COPD patients $(n=96)$

\begin{tabular}{|c|c|c|c|c|}
\hline Findings & $\begin{array}{c}\text { Stage } 2 \\
(n=33)\end{array}$ & $\begin{array}{c}\text { Stage } 3 \\
(n=35)\end{array}$ & $\begin{array}{c}\text { Stage } 4 \\
(n=28)\end{array}$ & $\begin{array}{c}P \\
\text { value } \\
\text { (Fishe } \\
\text { r exact } \\
\text { test) }\end{array}$ \\
\hline Dilated RA & $0(0 \%)$ & $\begin{array}{c}11 \\
(32.42 \%)\end{array}$ & $\begin{array}{c}25 \\
(89.28 \%)\end{array}$ & $<0.001^{\mathrm{s}}$ \\
\hline Dilated RV & $0(0 \%)$ & $\begin{array}{c}11 \\
(32.42 \%)\end{array}$ & $\begin{array}{c}25 \\
(89.28 \%)\end{array}$ & $<0.001^{\mathrm{s}}$ \\
\hline RVH & $0(0 \%)$ & $\begin{array}{c}15 \\
(42.86 \%)\end{array}$ & $21(75 \%)$ & $<0.001^{\mathrm{S}}$ \\
\hline $\begin{array}{l}\text { RV systolic } \\
\text { dysfunction }\end{array}$ & $0(0 \%)$ & $0(0 \%)$ & $\begin{array}{c}9 \\
(32.14 \%)\end{array}$ & $<0.001^{\mathrm{s}}$ \\
\hline $\begin{array}{l}\text { Pulmonary } \\
\text { hypertension }\end{array}$ & $\begin{array}{c}1 \\
(3.03 \%)\end{array}$ & $\begin{array}{c}16 \\
(45.71 \%)\end{array}$ & $\begin{array}{c}26 \\
(92.86 \%)\end{array}$ & $<0.001^{\mathrm{s}}$ \\
\hline $\begin{array}{l}\text { LV } \\
\text { diastolic } \\
\text { dysfunction }\end{array}$ & $\begin{array}{c}2 \\
(6.06 \%)\end{array}$ & $\begin{array}{c}6 \\
(17.14 \%)\end{array}$ & $\begin{array}{c}22 \\
(78.57 \%)\end{array}$ & $<0.001^{\mathrm{s}}$ \\
\hline $\begin{array}{l}\text { Others } \\
\text { Concentric }\end{array}$ & $\begin{array}{c}1 \\
(3.03 \%)\end{array}$ & $\begin{array}{c}1 \\
(2.86 \%)\end{array}$ & 0 & $0.656^{\mathrm{NS}}$ \\
\hline LVH & $0(0 \%)$ & $0(0 \%)$ & $2(7.14 \%)$ & $0.084^{\mathrm{NS}}$ \\
\hline $\begin{array}{l}\text { Pericardial } \\
\text { effusion }\end{array}$ & & & & \\
\hline
\end{tabular}

\section{S= Significant}

NS $=$ Not Significant

The Bar diagram shows, none of the stage 1 patients had pulmonary hypertension and only $1(100 \%)$ stage 2 patient had mild pulmonary hypertension. In stage 3, 16 patients had pulmonary hypertension. Among them 7 (43.7\%) had mild and $8(50 \%)$ had moderate pulmonary hypertension. While among stage 4 patients with pulmonary hypertension (26), $11(42.4 \%)$ had moderate and 14 (53.8\%) had severe pulmonary hypertension.

\section{Discussion}

Current study was done to assess the cardiac status of COPD patients. In this study among the 98 COPD patients males were predominant $(71.43 \%)$ with a male female ratio of 2.5:1. Alam et alshowed that the prevalence of COPD is three times higher in males than females. ${ }^{14}$

In this study, it was to be found that about one third of the patients were unemployed, mostly the severe COPD patients. Grønseth et al also showed same type of unemployment pattern in a subset analysis of BOLD study. ${ }^{15}$ This shows that advanced COPD incapacitates so much that most of these patients cannot do worthwhile job.

It was observed that $71 \%$ patients were smokers which is in coherence with Mahishale et al: ${ }^{16}$ In this study, all of the nonsmokers were females. However, all of them were passive smokers or resided in areas with heavy air pollution or had exposure to smoke from cooking in 'Chula'.

The prevalence of hypertension, diabetes and dyslipidemia in our study were $29.59 \%, 18.36 \%$ \& $12.24 \%$ respectively. The prevalence of hypertension and diabetes were higher in COPD patients than the national prevalence which are $21 \%$ and $8 \%$ respectively. ${ }^{17}$ The presence of respiratory impairment with respiratory symptoms are associated with a higher risk of having comorbid hypertension, diabetes and cardiovascular disease. ${ }^{18}$ The reasons for this associations are unclear but may be due to systemic inflammation, chronic infections, shared risk factors (such as smoking) or other unidentified factors.

It was observed that $51.01 \%$ COPD patients had abnormal echocardiographic findings. Freixa et al showed that the prevalence was $64 \% .{ }^{19}$ In their study about one third of the patients had previous history of cardiac diseases including coronary artery disease. But in our study these patients were excluded. This may be responsible for lower prevalence of echocardiographic abnormalities in our study.

The most common echocardiographic abnormality in this study was pulmonary hypertension (43.9\%). Various studies showed about 20-90\% COPD patients had elevated PASP on right heart catheterization. ${ }^{20,21} \mathrm{~A}$ study by Higham et alshowed a $55 \%$ prevalence of pulmonary hypertension 
among their study subjects. ${ }^{22}$ In their study most of the pulmonary hypertension were present in moderate to severe COPD patients, an observation also found in our study.

It was observed that most of the pulmonary hypertension among the stage 3 COPD patients were mild to moderate in severity. On the other hand stage 4 patients had moderate to severe pulmonary hypertension. A similar observation was also made by Mahishale et al. ${ }^{16}$

In current study we found that about $35 \%$ patients had right ventricular hypertrophy. Nishi et al found that the prevalence of RVH among COPD patients was $40 \%{ }^{23} \mathrm{We}$ also observed that $36 \%$ patients had dilated RA \&RV. RV systolic dysfunction was present in our study among $9.2 \%$ patients which is in coherence with Jatav et al. ${ }^{24}$

LV diastolic dysfunction (LVDD) was present in $30.6 \%$ patients in our study.Cuttica et al and Schoos et al found LVDD in $54 \% \& 66 \%$ COPD patients respectively. ${ }^{25,}{ }^{26}$ The higher prevalence rate in these studies were possibly due to enrollment of patients during exacerbations and due to presence of concomitant coronary artery disease.

In our study all the patients had normal LV ejection fraction. Kumar, Agrawal and Guptafound no significant difference of LVEF between the COPD and control group. ${ }^{27}$ In our study the patients with coronary artery disease were excluded which might explain the difference in our findings.

\section{Conclusion}

Our study showed that echocardiographic changes were very common in COPD patients specially at stage 3 and stage 4.Though these echocardiographic changes were absent in mild disease but the changes increased significantly with increasing severity of COPD. Since cardiovascular disease is one of the major cause of morbidity and mortality in COPD, it is essential to evaluate the cardiac status at the time of initial diagnosis by echocardiography. Thus overall survival \& quality of life can be improved by early detection and treatment of these abnormalities before they become irreversible.

\section{Acknowledgement}

We are grateful to the Department of Respiratory Medicine, DMCH for their kind cooperation.
Conflict of Interest: Authors declare no conflict of interest.

Funding: None

Ethical approval: IRB of Dhaka Medical College, Dhaka

Submitted: $22^{\text {nd }}$ March, 2020

Final revision received: $17^{\text {th }}$ November 2020

Accepted: $25^{\text {th }}$ November, 2020

Published: $1^{\text {st }}$ December, 2020

\section{References}

1. Snider GL. Nosology for our day: Its application to chronic obstructive pulmonary disease. Am J Respir Crit Care Med. 2003;167:678-83. DOI: $10.1164 / \mathrm{rccm} .200203-204 \mathrm{PP}$.

2. 2.Nussbaumer-Ochsner Y, Rabe KF. Systemic Manifestations of COPD. Chest. 2011 ;139:165-73. DOI: $10.1378 /$ chest.10-1252.

3. Barnes PJ, Celli BR. Systemic manifestations and comorbidities of COPD. Eur Respir J. 2009;33:1165-85.

DOI: $10.1183 / 09031936.00128008$.

4. Soriano JB, Visick GT, Muellerova H, Payvandi $\mathrm{N}$, Hansell AL. Patterns of Comorbidities in Newly Diagnosed COPD and Asthma in Primary Care. Chest. 2005;128:2099-107. DOI: 10.1378/chest.128.4.2099.

5. Anthonisen NR, Connett JE, Kiley JP, Altose MD, Bailey WC, Buist AS, et al. Effects of Smoking Intervention and the Use of an Inhaled Anticholinergic Bronchodilator on the Rate of Decline of FEV1. JAMA. 1994;272:1497. DOI: 10.1001/jama.1994.03520190043033.

6. Sin DD, Man SFP. Chronic Obstructive Pulmonary Disease as a Risk Factor for Cardiovascular Morbidity and Mortality. Proc Am Thorac Soc. 2005;2:8-11.

7. Sin DD. Mortality in COPD: The role of comorbidities. Chronic Obstr Pulm Dis CoMorbidities Syst Consequences. 2012;28(6):1-13. DOI: 10.1007/978-1-60761-673-3 1.

8. Robotham JL, Lixfeld W, Holland L, MacGregor D, Bryan AC, Rabson J. Effects of respiration on cardiac performance. J Appl Physiol. 1978;44:703-79.

DOI: 10.1152/jappl.1978.44.5.703.

9. Cannon CP, Battler A, Brindis RG, Cox JL, Ellis SG, Every NR et al. American College of Cardiology key data elements and definitions for measuring the clinical management and outcomes of patients with acute coronary syndromes: A report of the American College of Cardiology 
Task Force on Clinical Data Standards. J Am Coll Cardiol. 2001;38:2114-30.

DOI: 10.1016/S0735-1097(01)01702-8

10. Global Initiative for Chronic Obstructive Lung Disease. Pocket guide to COPD diagnosis, management and prevention: a guide for health care professionals. Glob Initiat Chronic Obstr Lung Dis Inc. 2018;

URL: goldcopd.org / wp-content / uploads/2018/ 02/WMS-GOLD-2018-Feb-Final-to-print-v2.pdf

11. Galiè N, Chairperson E, Humbert M, Chairperson E, Vachiery J-L, Gibbs S, et al. 2015 ESC/ERS Guidelines for the diagnosis and treatment of pulmonary hypertension ESC/ERS GUIDELINES IN PRESS | CORRECTED PROOF. Eur Hear J Eur Respir J Eur Respir J. 2015;1010:903-75.

DOI: 10.1093/eurheartj/ehp297.

12. Lang, R.M., Badano, L.P., Mor-Avi, V., Afilalo, J., Armstrong, A., Ernande, L. et al. Recommendations for Cardiac Chamber Quantification by Echocardiography in Adults: An Update from the American Society of Echocardiography and the European Association of Cardiovascular Imaging.Journal of the American Society of Echocardiography. 2015; 28, p.1-39.e14.

DOI: 10.1016/j.echo.2014.10.003

13. Nagueh SF, Smiseth OA, Appleton CP, Byrd BF, Dokainish $\mathrm{H}$, Edvardsen $\mathrm{T}$, et al. Recommendations for the Evaluation of Left Ventricular Diastolic Function by Echocardiography: An Update from the American Society of Echocardiography and the European Association of Cardiovascular Imaging I. General Principles for Echocardiographic Asses. J Am Soc Echocardiogr. 2016;29:277-314.

DOI: 10.1016/j.echo.2016.01.011.

14. Alam DS, Chowdhury MA, Siddiquee AT, Ahmed S, Clemens JD. Prevalence and determinants of chronic obstructive pulmonary disease (COPD) in Bangladesh. COPD J Chronic Obstr Pulm Dis. 2015;12:658-67.

DOI: 10.3109/15412555.2015.1041101.

15. Grønseth R, Erdal M, Tan WC, Obaseki DO, Amaral AFS, Gislason T, et al. Unemployment in chronic airflow obstruction around the world: Results from the BOLD study. Eur Respir J. 2017;50. DOI: 10.1183/13993003.00499-2017.

16. Mahishale V, Angadi N, Metgudmath V, Eti A, Lolly M, Khan S. Prevalence and impact of diabetes, hypertension, and cardiovascular diseases in chronic obstructive pulmonary diseases: A hospital-based cross-section study. J Transl Intern Med. 2016;3:155-60.

DOI: $10.1515 / \mathrm{jtim}-2015-0019$.

17. WHO | Noncommunicable diseases country profiles 2018. WHO. 2018;

URL:www.who.int/nmh/publications/ncdprofiles-2018/en/

18. Halbert RJ, Natoli JL, Gano A, Badamgarav E, Buist AS, Mannino DM. Global burden of COPD: Systematic review and meta-analysis. Eur Respir J. 2006;28:523-32.

DOI: $10.1183 / 09031936.06 .00124605$.

19. Freixa X, Portillo K, Paré C, Garcia-Aymerich J, Gomez FP, Benet M, et al. Echocardiographic abnormalities in patients with COPD at their first hospital admission. Eur Respir J. 2013;41:784-91. DOI: $10.1183 / 09031936.00222511$.

20. Weitzenblum E, Sautegeau A, Ehrhart M, Mammosser M, Hirth C, Roegel E. Long-term course of pulmonary arterial pressure in chronic obstructive pulmonary disease. Am Rev Respir Dis. $\quad 1984 ; 130: 993-8 . \quad$ DOI: 10.1164/arrd.1984.130.6.993. Burrows B, Knudson RJ, Cline MG, Lebowitz MD. Quantitative relationships between cigarette smoking and ventilatory function. Am Rev Respir Dis. 1977;115:195-205.

DOI: 10.1164/arrd.1977.115.2.195.

21. Higham MA, Dawson D, Joshi J, Nihoyannopoulos P, Morrell NW. Utility of echocardiography in assessment of pulmonary hypertension secondary to COPD. Eur Respir J. 2001;17:350-5.

DOI: 10.1183/09031936.01.17303500.

22. Nishi K, Sharma H, Darbari Hindu Rao Hospital L, Author C. TO evaluate the role of echocardiography in detecting right ventricular hypertrophy prior to ECG evidence of right ventricular hypertrophy.Internation Journal of Food and Nutritional Science.2014.

URL:www.ijfans.com/currentissue.html

23. Jatav VS, Meena SR, Jelia S, Jain P, Ajmera D, Agarwal V, et al. Echocardiographic findings in chronic obstructive pulmonary disease and correlation of right ventricular dysfunction with disease severity. Int J Adv Med. 2017;4:476. DOI: 10.18203/2349-3933.ijam20171045. 
24. Cuttica MJ, Shah SJ, Rosenberg SR, Orr R, Beussink L, Dematte JE, et al. Right Heart Structural Changes Are Independently Associated with Exercise Capacity in Non-Severe COPD. Morty RE, editor. PLoS One. 2011 29;6:e29069.

DOI: 10.1371/journal.pone.0029069.

25. Schoos MM, Dalsgaard M, Kjærgaard J, Moesby D, Jensen SG, Steffensen I, et al. Echocardiographic predictors of exercise capacity and mortality in chronic obstructive pulmonary disease. BMC Cardiovasc Disord. 2013;13.

DOI: $10.1186 / 1471-2261-13-84$.

26. Gupta N, Agrawal R, Srivastav A, Ved M. Echocardiographic evaluation of heart in chronic obstructive pulmonary disease patient and its corelation with the severity of disease. Lung India. 2011;28:105.

DOI: $10.4103 / 0970-2113.80321$. 